\title{
Adaptive foraging behaviour increases vulnerability to climate change
}

4 Benoit Gauzens ${ }^{1,2, *}$, Benjamin Rosenbaum ${ }^{1,2}$, Gregor Kalinkat ${ }^{3}$, Thomas Boy ${ }^{1,2}$, Malte

5 Jochum $^{4,5}$, Susanne Kortsch ${ }^{6}$, Eoin J. O'Gorman ${ }^{7}$, Ulrich Brose ${ }^{1,2}$

${ }^{1}$ EcoNetLab, German Centre for Integrative Biodiversity Research (iDiv) Halle-Jena-Leipzig,

8 Leipzig, Germany

92 Institute of Biodiversity, Friedrich Schiller University Jena, Jena, Germany

$10{ }^{3}$ Department of Ecohydrology, Leibniz Institute of Freshwater Ecology and Inland Fisheries

11 (IGB), Berlin, Germany

$12{ }^{4}$ Experimental Interaction Ecology, German Centre for Integrative Biodiversity Research (iDiv)

13 Halle-Jena-Leipzig, Leipzig, Germany

$14{ }^{5}$ Leipzig University, Institute of Biology, Leipzig, Germany

$15{ }^{6}$ Department of Agricultural Sciences, University of Helsinki, Finland

$16{ }^{7}$ School of Life Sciences, University of Essex, Wivenhoe Park, Colchester CO4 3SQ, UK

*Corresponding author: benoit.gauzens@idiv.de

\section{Abstract:}

Adaptative foraging behaviour should promote species coexistence and biodiversity under climate change as consumers are expected to maximise their energy intake, according to principles of optimal foraging theory. We test these assumptions using a unique dataset comprising (1) 22,185 stomach contents of fish species across functional groups and feeding strategies and (2) prey availability in the environment over 12 years. We explore how foraging behavior responds to variance in ecosystem productivity and temperature. Our results show that foraging shifts from trait-dependent prey selectivity to simple density dependence in warmer and more productive environments. Contrary to classical assumptions, we show that this behavioural change leads to lower consumption efficiency as species shift away from their optimal trophic niche. Dynamic food-web modeling demonstrates that this behavioral response to warming could undermine species persistence and biodiversity. By integrating empirical adaptive foraging behavior into dynamic models, our study reveals higher risk profiles for ecosystems under global warming. 


\section{Introduction}

Ecosystems are experiencing abrupt changes in climatic conditions, making it ever more important to predict and understand how they will respond to future changes. Global warming will affect various levels of biological organisation; from physiological processes occurring at the individual level ${ }^{1,2}$ to patterns at macroecological scales ${ }^{3,4}$. Warming impacts will cascade through these different organisational levels, changing species composition ${ }^{5}$ as well as community and food web structure ${ }^{6-8}$. By scaling up temperature effects from species physiology to food webs ${ }^{9}$, trophic interactions play a key role in the response of ecosystems to global warming ${ }^{10}$.

To assess the future of ecological communities, food web models that build on biological processes observed at the level of individual organisms can be used to translate mechanisms and predictions to the ecosystem level. For example, Allometric Trophic Networks ${ }^{11}$ (ATN) quantify effects of body mass and temperature on the biological rates of consumers and resources to predict species biomass changes over time and across environmental conditions ${ }^{11,12}$. Thus, ATNs facilitate understanding of how physiological responses to warming translate into species coexistence and biodiversity ${ }^{12}$. However, the ability of ATNs to derive sound predictions for large communities under changing environmental conditions has been challenged, stressing the need for more biological realism ${ }^{10,15}$. Indeed, a strong limitation of these models is that species are characterised by a set of biological rates that respond to temperature, such as metabolic or attack rates ${ }^{16-18}$. Therefore, species are limited to physiological response to warming, whereas the behavioural component is largely ignored. However it is well established that species also respond to warming by changing their behaviour ${ }^{19,20}$, and that this is a key variable in supporting species coexistence ${ }^{21-}$ ${ }^{25}$, which needs to be incorporated into food web models to improve their predictive power. Energetic demands increase with temperature, but species can offset this by adopting various strategies to increase their energy intake. Species can actively forage on more rewarding resources ${ }^{27,28}$, typically prey that are close to the maximum body mass that consumers can feed on $^{29}$. Therefore we expect that predators consume larger prey (trait-based selectivity) at higher temperatures, reducing predator-prey body mass ratios $(\mathrm{H} 1)$. Alternatively, individuals under high energetic stress may accept less rewarding (smaller, but more abundant) prey upon encounter $(\mathrm{H} 2)$ leading to a lower trait-based selectivity, and a trophic niche driven more by neutral processes (random encounter probability). The two proposed hypotheses would lead to contrasting effects on communities. Trait-based selectivity $(\mathrm{H} 1)$ may increase the strength of 
71 consumer interactions with a limited set of prey, depleting the latter's biomass. Alternatively, if

72 neutral processes are driving selectivity (H2), consumers will mostly forage on abundant

73 species, leading to a stronger control of their biomass, which could prevent competitive

74 exclusion and therefore enhance species coexistence ${ }^{25,32}$. To test these hypotheses, we

75 compiled a database of 22,185 stomach contents from 6 demersal fish species and analysed

76 the response of these consumers to changes in temperatures and productivity. Subsequently,

77 we addressed the consequences of these empirical relationships by integrating them into a

78 population-dynamical model to predict how species coexistence changes with warming.

\section{Response of fish to temperature and productivity gradients}

We used our database to document how consumer foraging behaviour responds to temperature and productivity. The six fish species considered belong to two functional groups differing in

84 body shape and foraging behaviour (flat, sit-and-wait predators versus fusiform, active hunters).

85 We used skewed normal distributions to fit the prey body mass distributions observed in fish

86 stomachs (hereafter called the realised distribution) and in their environment (hereafter called

87 the environmental distribution) (Fig. 1). The environmental distribution defines what is expected

88 if neutral processes drive fish diets: it represents the expected body mass distribution of prey in

89 fish stomachs if consumption were driven by density-based encounter rates only. However,

90 these two distributions are usually not identical, because consumers actively select prey with

91 specific body masses. We used the ratio of realised and environmental distributions to calculate

92 fish selectivity with respect to these different prey body masses to obtain a preference

93 distribution (see Fig. 1, Methods). This preference distribution describes consumer selectivity

94 based on traits (i.e. the prey body masses that allow an interaction) and consumer behavioural

95 decisions. 
98

99

100

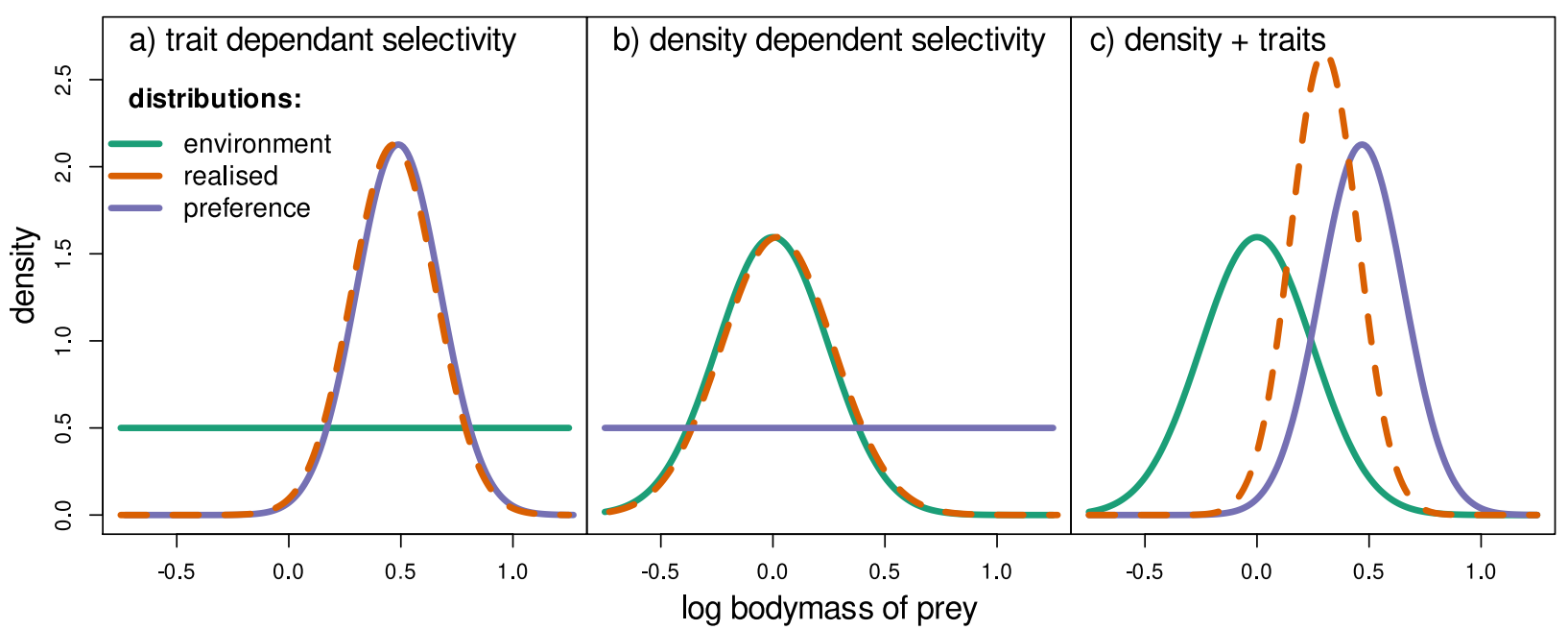

Fig. 1: Presentation of the different distributions of fish prey body mass. The environmental distribution (green) represents the distribution of prey body mass in the ecosystem. The realised distribution (dashed red) represents the body mass of the prey in a consumer stomach, and the preference distribution (blue) represents the selectivity of a consumer towards a specific prey body mass. a) All of the log prey body masses are equally represented in the environment so the distribution of prey body masses observed in a consumer's gut represents the body masses on which it actively foraged (its preference distribution) andpredation is driven by trait selectivity only (hypothesis 1). b) The body mass distribution of the prey observed in the gut and in the environment are equivalent, so the prey consumed by the predator were entirely driven by encounter probabilities (i.e. a neutral process), implying no active selectivity over specific prey size classes (hypothesis 2). Panels a) and b) represent extreme scenarios while real-world data are more likely to be described by two different distributions, as in c) where the body mass distribution of prey observed in the stomach and in the environment differs, so that the consumer specifically forages on some prey body masses that are represented by the preference distribution. High values in the preference distribution represent body masses that are over-represented in fish stomachs in comparison to what is available in the environment.

We first considered how the body mass distributions in consumer stomachs were changing with predator body mass and foraging strategy, as well as environmental conditions (temperature and productivity) using a linear model to predict the median of the realised distribution. We selected the most parsimonious model based on AIC. In cases of a significant interaction between temperature and productivity, we presented the effect of temperature at two different levels of productivity (which is a continuous variable) that correspond to the two modes of the distribution of environmental productivity (SI II). As expected ${ }^{33,34}$, we observed that the median of prey body mass increased with predator body mass (Fig. 2a, b, Table 1). 


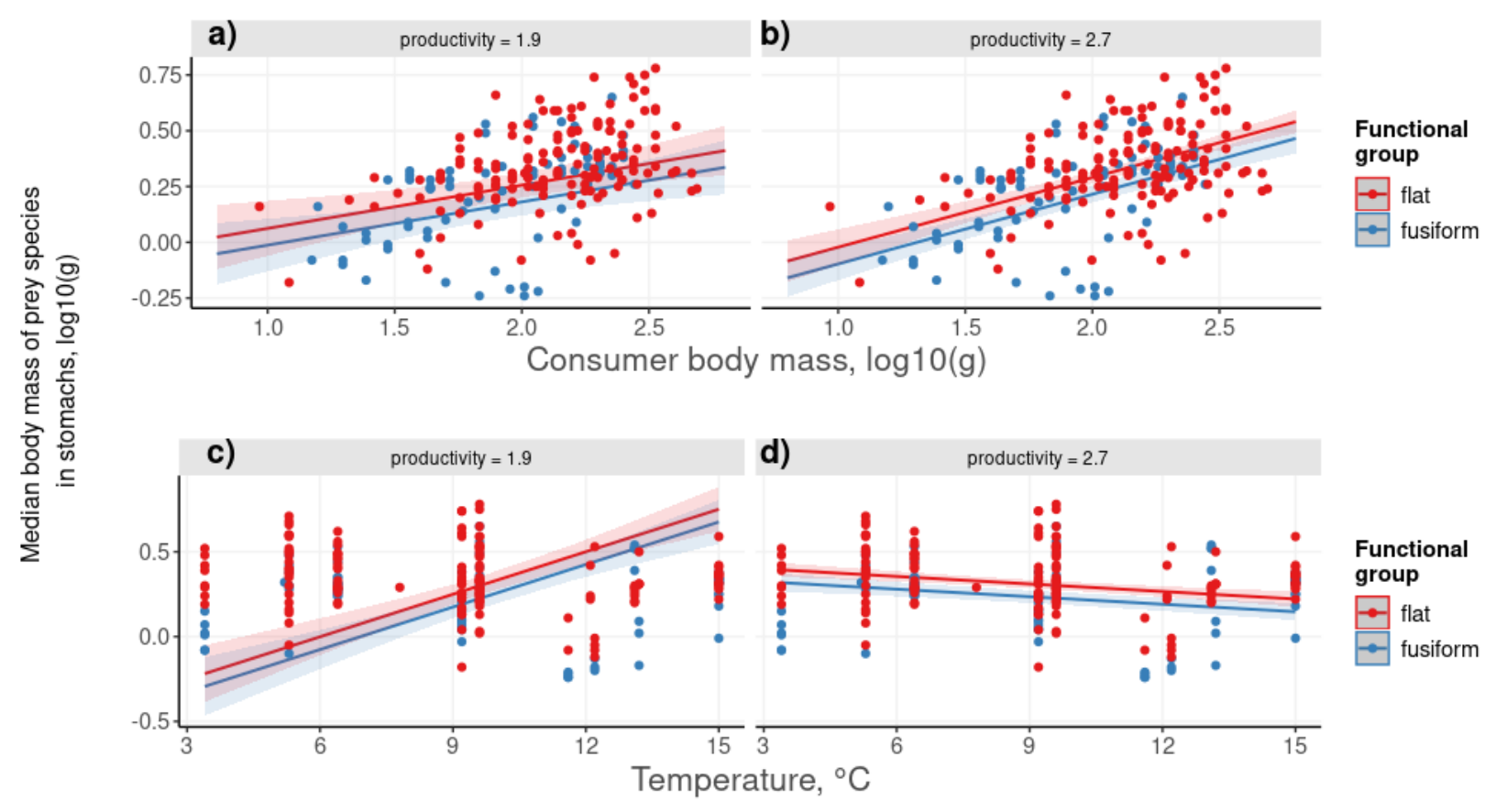

Fig. 2: Response of the median body mass of the realised prey body mass distribution to predator body mass $(a, b)$, and temperature $(c, d)$ at different productivity levels for the two fish functional groups. Points represent non-transformed data across all productivity levels and lines present model predictions. The shaded areas show the $95 \%$ confidence interval on the predicted values. Colours represent the fish functional groups (flat versus fusiforms).

The effect of temperature depended on environmental productivity: the body mass of consumed prey

\section{increased with temperature at low}

environmental productivity, but tended

to decrease at higher productivity (Fig 2c, d, Table 1). Interestingly, the response of prey body mass was identical for the two different predator body shapes and foraging strategies. These effects alone are insufficient to describe a change in fish behaviour as the distribution of prey body mass also changes along environmental
Table 1: response of the realised distribution to predator body mass and environmental gradients

\begin{tabular}{|c|c|c|c|}
\hline \multirow[b]{2}{*}{ Predictors } & \multicolumn{3}{|c|}{ ivieulall u ule reallseu uistrivulül } \\
\hline & Estimates & $\mathrm{Cl}$ & $p$ \\
\hline (Intercept) & -2.63 & $-3.68--1.57$ & $<0.001$ \\
\hline Predator body mass & -0.13 & $-0.50-0.25$ & 0.509 \\
\hline Productivity & 0.91 & $0.51-1.31$ & $<0.001$ \\
\hline Shape (fusiform) & -0.08 & $-0.12--0.03$ & 0.001 \\
\hline Temperature & 0.33 & $0.25-0.41$ & $<0.001$ \\
\hline pred. BM:Productivity & 0.16 & $0.01-0.30$ & 0.034 \\
\hline Productivity:Temperature & -0.13 & $-0.16--0.10$ & $<0.001$ \\
\hline Observations & \multicolumn{3}{|l|}{223} \\
\hline$R^{2} / R^{2}$ adjusted & \multicolumn{3}{|c|}{$0.449 / 0.434$} \\
\hline
\end{tabular}


gradients (SI II). To disentangle the effect of prey availability (neutral processes) from the fish behavioural response, we estimated the preference distribution that depicts fish selectivity independently of the environmental prey distribution (see Methods). We analysed the response of this fish preference distribution in the same way as for the realised distribution. Our results confirm the importance of species traits for structuring trophic interactions, as larger fish are foraging on larger prey (Fig. 3a). They also emphasize that ecosystem productivity alters the temperature-dependence of fish foraging behaviour with a significant interaction between temperature and productivity (Fig 3b, Table 2). The temperature effect was only significant above a productivity threshold of $10^{2.52}$ (SI III) indicating that fish only adapted their feeding behaviour to temperature by foraging on smaller prey in warmer conditions when resources were plentiful. We did not detect any interaction between fish shape and other covariates, suggesting that the behavioural responses to temperature and productivity are similar for fish species with different body shape and foraging strategies.

a)

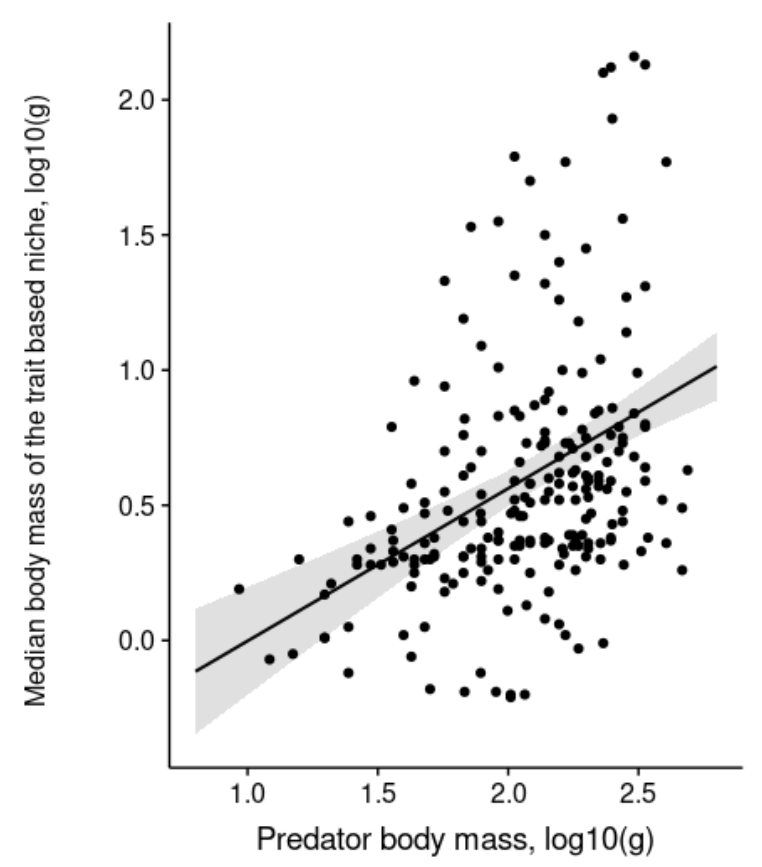

b)

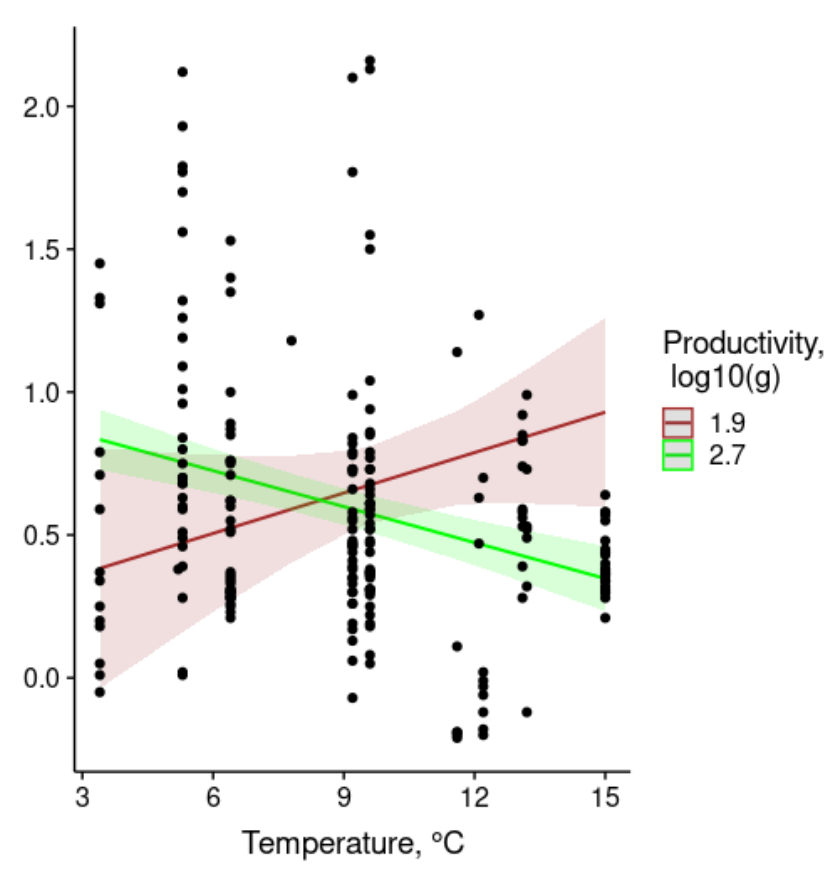

Fig. 3: Response of the median prey body mass of the preference distribution to predator body mass, temperature and productivity. Points represent non-transformed data across all productivity levels and lines represent model predictions. The shaded areas show the $95 \%$ confidence interval on the predicted values. Grey and green colour represent two different productivity levels at which the temperature effect 
167 The energetic stress that warming imposes on individuals through increased metabolic rates should be mitigated by higher feeding rates at higher prey availability in more productive environments. Thus, because the effects of temperature and productivity should cancel each other out, we expected a stronger adaptive response at low productivity, where consumers must cope with maximum energetic stress. Surprisingly, we did not find a significant effect of temperature on preference for prey sizes in the least productive environments (Fig. 3b, SI III). One explanation for this may relate to the generally low productivity of the Baltic Sea at the period of our study ${ }^{35,36}$. At very low productivity, fish are experiencing high energetic stress (regardless of temperature) because resource density is low and they cannot afford to miss a prey upon encountering it, even if this prey is far from their preferred body size. Under such stressful conditions, there may be no scope for predators to adapt their feeding behaviour as temperature increases. In more productive environments, feeding behaviour may be less constrained, increasing the adaptive capacity of the fish. Indeed, under such conditions, a cold temperature corresponds to low energetic stress due to a combination of low energetic demand and high resource availability), which allows fish to select prey based on traits. However, warming increases energetic stress because the resource availability is similar whereas the energetic demand rises, forcing fish to engage in non-selective behaviour.

Therefore, our results support hypothesis 2 that as temperature increases in productive environments, fish become less selective for prey size so as not to miss foraging opportunities, which is consistent with what happens at any temperature when productivity is low. This feeding behaviour, which lowers trait-based selectivity, imposes several disadvantages on consumers. As smaller prey are more abundant, consumers miss out on larger and thus energetically more rewarding resources while handling smaller prey. Indeed, our analyses reveal that consumers miss these larger prey, as we observed a very weak and negative temperature effect on the width of consumer trophic niches (SI IV). This suggests that the increased consumption of smaller prey in warmer environments happens at the cost of missing out on larger prey, which can be critical to satisfying the energetic needs of consumer species ${ }^{37}$. This observation tends

195 to mitigate our assumption that adaptive behaviour leading to more neutral-driven consumption 196 should increase species coexistence in the face of warming. Indeed, metabolic rates increase 197 with warming faster than feeding rates, leading to the extinction of top predators due to 198 starvation ${ }^{31,38,39}$. This starvation effect explained by physiological process can cumulate with our 199 observed behavioural response: consuming outside of the most efficient predator-prey body 200 mass ratio is, in general, associated with a lower energy flux through food webs, which may limit 
the coexistence of consumer species ${ }^{37,40}$. The combination of direct and indirect effects of warming could increase the likelihood of extinction of top predators in food webs, which are usually considered key species for the maintenance of biodiversity and ecosystem

204 functionality ${ }^{41}$.

\section{Consequences for species coexistence under global warming}

Adaptive foraging in response to varying local conditions is often considered to foster species coexistence $e^{25,26,42}$. The general assumption behind this conclusion is that consumer species will adapt their foraging strategies in order to maximise their energetic gains ${ }^{43}$. However, our results,

211 based on an allometric framework, suggest that consumers tend to depart from this optimal

212 behaviour under stressful conditions. We explored the consequences of this behaviour using a

213 population dynamic model that predicts the temporal dynamics and coexistence of species in

214 food webs. The model was parameterized with species body masses and temperature (see

215 Methods). We ran two versions of this model: one including adaptation of species diets to local

216 temperature and productivity conditions as informed by our empirical results, and one without

217 this adaptation, corresponding to the classical modelling approach ${ }^{44}$. We simulated the

218 dynamics for synthetic food webs of 50 species (30 consumers and 20 basal species) over a

219 temperature gradient spanning from $1^{\circ} \mathrm{C}$ to $25^{\circ} \mathrm{C}$ to predict the number of extinctions at different

220 temperatures. Overall, we observed that models incorporating adaptive foraging were more

221 sensitive to warming (Fig. 4), as for models without behavioural adaptation the proportion of

222 extinct species remained low over a larger temperature gradient. These results were not

223 affected by the choice of specific values for ecosystem nutrient availability or the functional

224 response type that are free parameters of our model (SI V) 


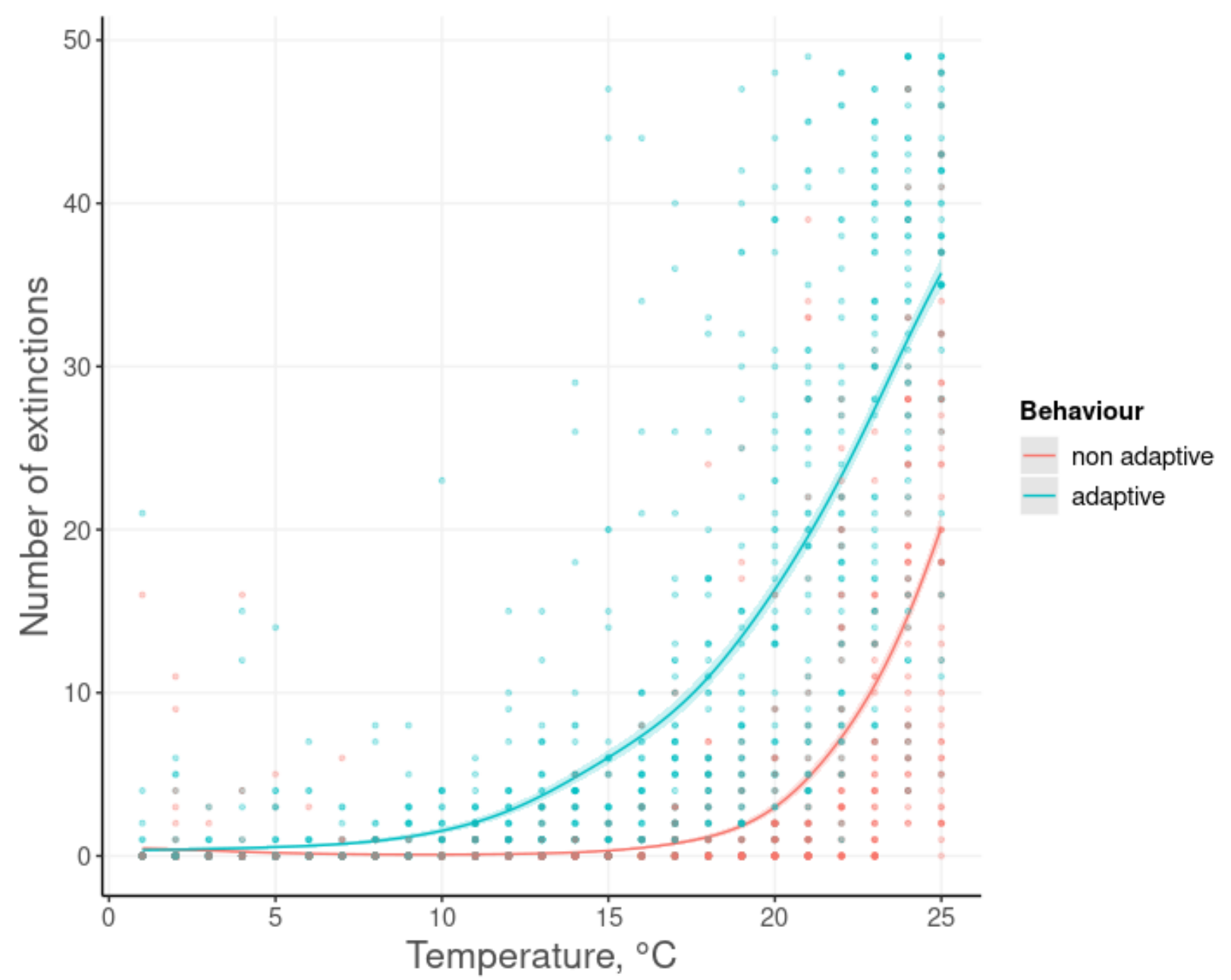

Fig. 4: Number of species extinctions predicted by the model at different temperatures. The blue line represents the model output with adaptation of species' diet to local temperature and productivity conditions was considered, the red line shows extinctions without allowing for this adaptation. The shaded areas show the $95 \%$ confidence interval on the predicted values. Predictions were estimated using a GAM (REML method) with a binomial link function.

234 The effects of warming on the trait structure of communities ${ }^{8}$ and the distribution of trophic

235 interactions ${ }^{7}$ are well documented, but a framework for integrating changes in feeding

236 behaviour with a general modelling approach has been lacking. Our results stress the

237 importance of accounting for foraging behaviour to better understand and predict community

238 responses to climate change and challenge previous conclusions on this topic. Indeed, the

239 discrepancies between the models with and without adaptive foraging suggest that the classical

240 approach, which only accounts for changes in species physiology ${ }^{10,12}$, may have overlooked a

241 significant portion of species responses to warming. Importantly, our results show that, contrary 
242 to common expectation, behavioural adaptations in response to climatic stress reduce the

243 likelihood of species coexistence and community biodiversity.

\section{Future directions}

The similarity in responses between the two feeding strategies (sit-and-wait and active foraging)

248 of our consumer species indicates some generality of our results, but it is now important to

249 further generalize our results across a wider range of species and ecosystem types. For

250 instance, metabolic type has an important effect on the response of species to temperature ${ }^{45}$

251 and endotherms could respond differently to ectotherms such as fish.

252 Generally, food web models incorporating foraging behaviour are based on optimal foraging

253 theory and thus miss a data-driven description of how consumers' diet selectivity changes in a

254 natural context. To address this, we developed a trait-based framework to document the

255 response of foraging behaviour to temperature that can be incorporated into predictive food web

256 models and allowing us to derive predictions on species coexistence. Our approach can be

257 generalised to other ecological variables that affect food webs and foraging behaviour, such as

258 fear of predators ${ }^{30}$ or habitat complexity ${ }^{46}$ for instance. Finally, the effects documented here

259 come from data sampled at rather low temperatures and levels of productivity. Therefore, it is

260 crucial to extend our regression models to more productive and warm ecosystems. For

261 instance, one can argue that very high levels of productivity would balance the energetic stress

262 related to temperature increase, limiting fish adaptive response to warming in eutrophic

263 environments.

\section{Conclusion}

It is generally assumed that consumers respond to environmental conditions by making optimal choices maximising their energetic income $e^{26,47,48}$. This assumption was used to derive several predictions in ecology about community structure and species coexistence. For instance, it is often considered as a solution to May's paradox ${ }^{49}$ based on the discrepancy between the prediction of a mathematical model posing that complex communities should not persist in nature and empirical observations of ecosystem complexity. It is therefore usually assumed that

273 species' behaviour is a strong driver of community organisation and supports species

274 coexistence. We challenge this optimistic view of nature by emphasizing that under stressful

275 conditions, when resources are scarce and species energetic needs high - for instance when 
276 they face energetic stress caused by temperature increase - consumer species tend to depart

277 from what would be their optimal behaviour under low-stress conditions. Therefore, the

278 ecological conclusions built into the assumptions that adaptive behaviour favours coexistence

279 do not necessarily hold in the context of global warming. We tested the consequences of our

280 observations by integrating this behavioural response in a mechanistic model. We show that the

281 number of species extinctions in response to an increase in temperature is higher than what is

282 observed without. This means that the consequences of global warming for species coexistence

283 might be more severe than predicted by classical ecological models. Our findings also challenge

284 the general paradigm that adaptive foraging should mitigate the consequences of global

285 warming for natural ecosystems. Instead, the drastic consequences of climate change indicated

286 by our results call for a general data-driven theory-approach to forecast of biodiversity and

287 functioning in future ecosystems.

Acknowledgements

291 We are profoundly grateful that Wolf E. Arntz collected and provided the valuable data set from 292 his early work in Kiel Bay that we used in this study. We are also thankful to Astrid Jarre who 293 digitised the stomach content data, Ute Jacob for her help in the early phase of this project and 294 Carlos Melian for his friendly review of the manuscript. BG, UB, BR, TB, MJ gratefully 295 acknowledge the support of iDiv funded by the German Research Foundation (DFG-FZT 118, 296 202548816). GK acknowledges funding from the German Academic Exchange Service (DAAD, 297 57070483). MJ acknowledges funding by the European Research Council (ERC) under the 298 European Union's Horizon 2020 research and innovation programme (grant agreement no. 299 677232).

\section{References}

303 1. Dell, A. I., Pawar, S. \& Savage, V. M. Systematic variation in the temperature 304 dependence of physiological and ecological traits. Proc. Natl. Acad. Sci. U. S. A. 108, 305 10591-10596 (2011).

306 2. Seebacher, F., White, C. R. \& Franklin, C. E. Physiological plasticity increases resilience 307 of ectothermic animals to climate change. Nat. Clim. Chang. 5, 61-66 (2015). 
3. Yvon-Durocher, G., Jones, J. I., Trimmer, M., Woodward, G. \& Montoya, J. M. Warming alters the metabolic balance of ecosystems. Philos. Trans. R. Soc. B Biol. Sci. 365, 2117-2126 (2010).

4. Free, C. M. et al. Impacts of historical warming on marine fisheries production. Science (80-. ). 363, 979-983 (2019).

5. Lenoir, J. et al. Species better track climate warming in the oceans than on land. Nat. Ecol. Evol. 4, 1044-1059 (2020).

6. Weinbach, A., Allhoff, K., Thebault, E., Massol, F. \& Loeuille, N. Selective effects of

7. Gibert, J. P. Temperature directly and indirectly influences food web structure. Sci. Rep. temperature on body mass depend on trophic interactions and network position. bioRxiv

8. O'Gorman, E. J. et al. A simple model predicts how warming simplifies wild food webs.

9. Petchey, O. L., Brose, U. \& Rall, B. C. Predicting the effects of temperature on food web

10. Gauzens, B., Rall, B. C., Mendonça, V., Vinagre, C. \& Brose, U. Biodiversity of intertidal food webs in response to warming across latitudes. Nat. Clim. Chang. 10, 264-269 (2020).

11. Martinez, N. D. Allometric Trophic Networks From Individuals to Socio-Ecosystems: Ecology and Evolution vol. 892 (2020).

12. Binzer, A., Guill, C., Rall, B. C. \& Brose, U. Interactive effects of warming, eutrophication and size structure: Impacts on biodiversity and food-web structure. Glob. Chang. Biol. 22, 220-227 (2016).

13. Boit, A., Martinez, N. D., Williams, R. J. \& Gaedke, U. Mechanistic theory and modelling of complex food-web dynamics in Lake Constance. Ecol. Lett. 15, 594-602 (2012).

14. Curtsdotter, A. et al. Ecosystem function in predator-prey food webs-confronting dynamic models with empirical data. J. Anim. Ecol. 88, 196-210 (2019).

15. Sauve, A. M. C. \& Barraquand, F. From winter to summer and back: Lessons from the parameterization of a seasonal food web model for the Białowieża forest. J. Anim. Ecol. 89, 1628-1644 (2020).

16. Rall, B. C. et al. Universal temperature and body-mass scaling of feeding rates. Philos. Trans. R. Soc. B Biol. Sci. 367, 2923-2934 (2012). 
17. Gilbert, B. et al. A bioenergetic framework for the temperature dependence of trophic interactions. Ecol. Lett. 17, 902-914 (2014).

18. Bideault, A. et al. Thermal mismatches in biological rates determine trophic control and biomass distribution under warming. Glob. Chang. Biol. 27, 257-269 (2021).

19. Abram, P. K., Boivin, G., Moiroux, J. \& Brodeur, J. Behavioural effects of temperature on ectothermic animals: unifying thermal physiology and behavioural plasticity. Biol. Rev. 92,

21. Abrams, P. A. Dynamics and Interactions in Food Webs with Adaptive Foragers. in Food

22. Abrams, P. \& Matsuda, H. Effects of adaptive predatory and anti-predator behaviour in a

23. Valdovinos, F., Ramos-Jiliberto, R., Garay-Narva' ez, L., Pasquinell, U. \& Dunne, J. A.

24. Kondoh, M. Foraging adaptation and the relationship between food-web complexity and stability. Science (80-. ). 299, 1388-1391 (2003).

25. Kondoh, M. Does foraging adaptation create the positive complexity-stability relationship in realistic food-web structure? J. Theor. Biol. 238, 646-51 (2006).

26. Kondoh, M. Foraging adaptation and the relationship between food-web complexity and stability. Science (80-. ). 299, 1388-91 (2003).

27. Lemoine, N. P., Drews, W. A., Burkepile, D. E. \& Parker, J. D. Increased temperature alters feeding behavior of a generalist herbivore. Oikos 122, 1669-1678 (2013).

28. Sentis, A., Hemptinne, J. L. \& Brodeur, J. Towards a mechanistic understanding of temperature and enrichment effects on species interaction strength, omnivory and foodweb structure. Ecol. Lett. 17, 785-793 (2014).

29. Portalier, S. M. J., Fussmann, G. F., Loreau, M. \& Cherif, M. The mechanics of predatorprey interactions: First principles of physics predict predator-prey size ratios. Funct. Ecol. 33, 323-334 (2019).

30. Ho, H., Tylianakis, J. M., Zheng, J. X. \& Pawar, S. Predation risk influences food-web structure by constraining species diet choice. Ecol. Lett. 22, 1734-1745 (2019).

31. Binzer, A., Guill, C., Brose, U. \& Rall, B. C. The dynamics of food chains under climate 
change and nutrient enrichment. Philos. Trans. R. Soc. B Biol. Sci. 367, 2935-2944

(2012).

32. Gauzens, B., Legendre, S., Lazzaro, X. \& Lacroix, G. Intermediate predation pressure leads to maximal complexity in food webs. Oikos 125, 595-603 (2016).

33. Tsai, C.-H., Hsieh, C. \& Nakazawa, T. Predator-prey mass ratio revisited: Does preference of relative prey body size depend on individual predator size? Funct. Ecol. (2016) doi:10.1111/1365-2435.12680.

34. Brose, U. et al. Predator traits determine food-web architecture across ecosystems. Nat. Ecol. Evol. 3, 919-927 (2019).

35. Elmgren, R. \& Hill, C. Ecosystem function at low biodiversity - the Baltic example. in Marine Biodiversity 319-336 (Cambridge University Press, 2010). doi:10.1017/cbo9780511752360.015.

36. Elmgren, R. Man's impact on the ecosystem of the Baltic Sea: Energy flows today and at the turn of the century. Ambio 18, 326-332 (1989).

37. Brose, U. Body-mass constraints on foraging behaviour determine population and foodweb dynamics. Funct. Ecol. 24, 28-34 (2010).

38. Petchey, O. L., McPhearson, P. T., Casey, T. M. \& Morin, P. J. Environmental warming alters food-web structure and ecosystem function. Nature 402, 69-72 (1999).

39. Vucic-Pestic, O., Ehnes, R. B., Rall, B. C. \& Brose, U. Warming up the system: Higher predator feeding rates but lower energetic efficiencies. Glob. Chang. Biol. 17, 1301-1310 (2011).

40. Guzman, L. M. \& Srivastava, D. S. Prey body mass and richness underlie the persistence of a top predator. Proc. R. Soc. B Biol. Sci. 286, (2019).

41. Birkeland, C. \& Dayton, P. K. The importance in fishery management of leaving the big ones. Trends in Ecology and Evolution vol. 20 356-358 (2005).

42. Stump, S. M. \& Chesson, P. How optimally foraging predators promote prey coexistence in a variable environment. Theor. Popul. Biol. 114, 40-58 (2017).

43. Pyke, G. H., Pulliam, H. R. \& Charnov, E. L. Optimal Foraging: A Selective Review of Theory and Tests. Q. Rev. Biol. 52, 137-154 (1977).

44. Schneider, F. D., Brose, U., Rall, B. C. \& Guill, C. Animal diversity and ecosystem functioning in dynamic food webs. Nat. Commun. 7, 1-8 (2016). vulnerability to warming of marine versus terrestrial ectotherms. Nature 569, 108-111 (2019). 
46. Jinks, K. I. et al. Habitat complexity influences the structure of food webs in Great Barrier Reef seagrass meadows. Ecosphere 10, e02928 (2019).

47. Beckerman, A. P., Petchey, O. L. \& Warren, P. H. Foraging biology predicts food web complexity. Proc. Natl. Acad. Sci. U. S. A. 103, 13745-9 (2006).

48. Petchey, O. L., Beckerman, A. P., Riede, J. O. \& Warren, P. H. Size, foraging, and food web structure. Proc. Natl. Acad. Sci. U. S. A. 105, 4191-4196 (2008).

49. May, R. M. Qualitative Stability in Model Ecosystems. Ecology 54, 638-641 (1973).

50. Russo, T., Costa, C. \& Cataudella, S. Correspondence between shape and feeding habit changes throughout ontogeny of gilthead sea bream Sparus aurata L., 1758. J. Fish Biol. 71, 629-656 (2007).

51. Arntz, W. E. Die Nahrung juveniler Dorsche (Gadus morhuaL.) in der Kieler Bucht. in

52. Lie, U. \& Pamatmat, M. M. digging characteristics and sampling efficiency of the $0.1 \mathrm{~m} 2$ van veen grab. Limnol. Oceanogr. 10, 379-384 (1965).

53. Gröger, J. \& Rumohr, H. Modelling and forecasting long-term dynamics of Western Baltic macrobenthic fauna in relation to climate signals and environmental change. J. Sea Res. 55, 266-277 (2006).

54. Stan Development Team. RStan: the R interface to Stan. (2020).

55. Azzalini, A. The R package sn: The Skew-Normal and Related Distributions such as the Skew-t and the SUN (version 2.0.0). (2021).

56. Jobling, M. Mythical models of gastric emptying and implications for food consumption studies. Environ. Biol. Fishes 16, 35-50 (1986).

57. Yodzis, P. \& Innes, S. Body Size and Consumer-Resource Dynamics. Am. Nat. 139, 1151-1175 (1992).

58. Lang, B., Ehnes, R. B., Brose, U. \& Rall, B. C. Temperature and consumer type dependencies of energy flows in natural communities. Oikos 126, 1717-1725 (2017).

59. Hirt, M. R., Lauermann, T., Brose, U., Noldus, L. P. J. J. \& Dell, A. I. The little things that run: a general scaling of invertebrate exploratory speed with body mass. Ecology 98 , 2751-2757 (2017). 


\section{Supplementary information I Methods}

The Kiel Bay is located in the Baltic Sea, which is a marginal sea connected to the North Atlantic and considered the largest brackish sea in the world. It is a rather low productivity ecosystem with low biodiversity due to its glazial history and the strong salinity gradients that only few species can tolerate ${ }^{35,36}$. The core of the Kiel Bay database comprises detailed diet information based on stomach contents from 22185 fish individuals of six species from the Kiel Bay. These species were classified into two functional groups based on their body shape and habitat use: fusiform and benthopelagic species (Gadus morhua, Merlangius merlangius) versus flat and demersal species (Limanda limanda, Pleuronectes platessa, Platichthys flesus, and Hippoglossoides platessoides). This shape characteristic also corresponds to specific foraging behaviour ${ }^{50}$.

458 The fish individuals were sampled using systematic and standardised bottom trawls. The trawls were carried out year-round between 1968 and 1978. The body lengths of fish were measured and rounded to the nearest integer (in $\mathrm{cm}$ ). Species-specific regressions were used to estimate fish body masses. Stomach contents were identified to the highest taxonomic resolution possible and wet mass determined when possible. Hence, the database includes body size data for all fish (i.e. predators) but also for prey items from the stomach contents ${ }^{51}$. In addition, we were able to add independently-sampled abundance and body mass information on the benthic invertebrate (i.e. prey) fauna to the database. These data on prey abundances and body masses were sampled independently at the trawling locations using classical $0.1 \mathrm{~m}^{2}$ van Veen grabs ${ }^{52}$, see ${ }^{53}$ for detailed procedure. We have enriched the database with climatic (i.e. temperature) and oceanographic (i.e. salinity) data and geographical information on the distances between the sampling (trawling) sites. So far, the stomach content data have been published only partially and in German language ${ }^{51}$ while parts of the invertebrate abundance data were treated and published separately ${ }^{53}$. The food web mainly consists of six demersal fish

472 species and more than a dozen benthic invertebrate species from different groups (see Table SI 473 VI 3). 
477 To make comparisons between the distributions of prey observed in fish stomachs and the ones

478 observed in the environment, we only used a subset of the database for which we were able to

479 (i) associate information about a fish to information about its environment and (ii) have a body

480 mass estimate of prey found in the stomach. We considered this association between fish and

481 environment possible, when they were sampled in the same area and within less than 31 days.

482 This first filter reduced the number of fish used in our analysis to 2,487.

483 On this subset, we considered a unique statistical individual (hereafter called statistical fish) all

484 individuals from the same functional group, occurring at the same place, on the same date with

485 the same body mass. This choice is led by the allometric approach used in our analysis, where

486 all individuals from the same species and with the same body mass are considered identical.

487 This aggregation increases the quality of the estimation of the prey body mass distribution in

488 stomachs at the cost of a lower statistical power for the analyses done on the shape of these

489 distributions. For instance, with a high aggregation level, fewer data points are available to

490 consider the effect of temperature on the average body mass of prey. This approach is therefore

491 conservative as it reduces the probability of type 1 error. Lastly, we found that few fishes were

492 mostly feeding on species that were not detected in the environment, suggesting that the

493 information on the environment was not a good descriptor of available resources. When less

494 than $90 \%$ of the prey biomass found in guts was explained by what was found in the

495 environment, the fish were discarded (26 cases) Finally, we obtained a final dataset of 290

496 statistical fish. For our statistical analysis we used fish shape as a covariate instead of fish

497 species. As some species where specific to some temperature or body mass gradients, the

498 species-specific slopes obtained would be meaningless. This question only holds for the

499 analysis about the fish stomach contents. For the analysis of preferences, fish shape or fish

500 species covariate were anyway removed by our AIC criterion.

501 Different factors affect prey retention time in consumers' guts. Temperature is certainly essential

502 but we assume that its impact was the same for all consumers introducing a constant bias with

503 no effect on the trends we observed. However, a more species-specific factor relating to species

504 morphology, like the presence of shells or skeletons, could impact our results. We thus

505 compared two sets of results, one for which we incorporated in the model a lower detection

506 probability for species with hard bodies (presented here), and one for which we did not (SI VI).

507 Overall, the trends and effects observed when including this correction were similar to those

508 observed without correction, thus suggesting an absence of systematic biases.

509 

environment distributions, we fitted skew normal distributions to the observed body masses $y$, with environment $I D$ as a random effect. A skew normal distribution is defined by parameters for location $\xi$, scale $\omega$ and shape $\alpha$. Its probability density function reads

$$
p(y \mid \xi, \omega, \alpha)=\frac{1}{\omega \sqrt{2 \pi}} \exp \left(\frac{-(y-\xi)^{2}}{2 \omega^{2}}\right)\left(1+\operatorname{erf}\left(\alpha \frac{y-\xi}{\omega \sqrt{2}}\right)\right)
$$

where erf is the Gaussian error function ${ }^{54,55}$. For $\alpha=0$, this reduces to the non-skewed normal distribution with mean $\mu=\xi$ and standard deviation $\sigma=\omega$. For $\alpha>0$ or $\alpha<0$, the distribution is positively or negatively skewed, where skew $\gamma(\alpha)$, standard deviation $\sigma(\omega, \alpha)$ and mean $\mu(\xi, \omega, \alpha)$ are given as functions of location, scale and shape parameters ${ }^{55}$.

The statistical model then is defined by an observed body mass $y$ of a prey individual $i$ in environment $I D(i)$ being distributed as

$$
y_{i, I D} \operatorname{skewnormal}\left(\xi_{I D}, \omega_{I D}, \alpha_{I D}\right)
$$

$(i=1, \ldots, N, I D=1, \ldots, M)$. Using a hierarchical / partial pooling approach, we assume the individual parameters have a joint multivariate normal distribution

$$
\left(\xi_{I D}, \omega_{I D}, \alpha_{I D}\right) \text { multivariatenormal }((\dot{\xi}, \dot{\omega}, \dot{\alpha}), \Sigma)
$$
$(I D=1, \ldots, M)$. The joint mean parameters $\dot{\xi}, \dot{\omega}, \dot{\alpha}$ and the $3 \times 3$ covariance matrix $\Sigma$ are estimated during the model fitting approach. We used weakly informative priors for all model parameters. Samples from the posterior distribution were drawn using Hamiltonian Monte Carlo in Stan ${ }^{54}$ and posterior medians were used as point estimates of $\left(\xi_{I D}, \omega_{I D}, \alpha_{I D}\right)$ for the subsequent analyses. The realised distributions were fitted analogously, using predator identity as a random effect. We however included here a correction factor to consider that the probability of detection of prey in guts relates to their body characteristic ${ }^{56}$ (presence or absence of hard body parts like shells or skeleton). We assumed that prey with hard body parts are more likely to be detected in comparison to species composed of soft tissues only because of higher digestion time and corrected their biomass by multiplying it by 0.8 . The results found without this correction were similar to the ones observed without (SI VI). 
The preference distributions of each statistical fish were estimated as the departure of

543 the realised niche from the environmental distribution. We removed the effect of species

544 environmental availability from the realised to define the preference distribution as:

$545 P=\frac{R}{E}$

546 where $P, R$ and $E$ represent the preference, realised and environmental distributions,

547 respectively. By doing so, we assumed that a feeding event is defined by two independent

548 probabilities: the probability for a consumer to encounter a prey (defined by the $R$ distribution)

549 and of the probability for a consumer to consume the prey when encountered (given by the

550 preference distribution). To assess changes in the distributions and how they depart from each

551 other, we used variations in the point estimates (median and standard deviation). This limited

552 the amount of information used in our study. Quantifying the neutral versus trait-based

553 processes would benefit from the comparison between the environmental and realised

554 distributions using metrics like the Kullback-Leibler divergence. With such an approach, one

555 could argue that the more divergent the distributions are, the more predation events are driven

556 by traits. However, this would be limited by the impossibility of disentangling the part of the

557 divergences explained by changes in the environmental distribution and what relates to a

558 change in fish behaviour. However, we believe that a more controlled approach in micro- or

559 mesocosms where the body mass distribution of prey species available could be standardised

560 could elegantly solve this issue.

\section{Dynamic model}

To simulate the population dynamics, we used a previously published model ${ }^{44}$, based on the Yodzis and Innes framework ${ }^{57}$. The growth of consumer species $B_{i}$ is determined by the balance between its energetic income (predation) and its energetic losses (predation

567 metabolism)

$\frac{d B_{i}}{d t}=e_{P} B_{i} \sum_{j} F_{i j}+e_{A} B_{i} \sum_{j} F_{i j}-\sum_{j} B_{l} F_{j i}-x_{i} B_{i}$,

570 where $e_{p}=0.545$ and $e_{a}=0.906$ represent the assimilation efficiency of a consumer foraging on

571 plants and animals, respectively ${ }^{58}$. $x_{i}$ defines the metabolic rate of species $i$, which scales

572 allometrically with body mass:

573 $x_{i}=x_{0} m_{i}^{-0.25} e^{E_{x} \frac{T_{0}-T}{k T_{0} T}}$ 
574 where $x_{0}=0.314$ is the scaling constant ${ }^{44}, E_{x}=-0.69$ is the activation energy of metabolic rate

575 (Binzer et al. 2015), $k$ the Boltzmann constant, $T_{0}=293.15$ the reference temperature in Kelvin

576 and $T$ the temperature at which the simulation is performed. The trophic interactions are

577 determined using a functional response $F_{i j}$ that describes the feeding rate of consumer $i$ over

578 resource $j$ :

579

$$
F_{i j}=\frac{\omega_{i j} b_{i j} B_{j}^{1+q}}{1+c B_{i}+\omega_{i j} \Sigma_{k} h_{i j} b_{i k} B_{k}^{1+q}} \cdot \frac{1}{m_{x}} .
$$

580

$b_{i j}$ represent the species-specific capture and is determined by predator and prey body masses: $b_{i j}=P_{i j} L_{x z}$.

583 It corresponds to the product of encounter probabilities $P_{i j}$ by the probability that an encounter

584 leads to a realised predation event $L_{i j}$. Both quantities are determined by species body masses.

585 We assume that encounter probability is more likely for species with higher movement speeds 586 of both consumer and resource species:

$$
P_{i j}=p_{0} m_{i}^{\beta_{i}} m_{j}^{\beta_{j}} e^{E_{p} \frac{T_{0}-T}{k T_{0} T}}
$$

588 Since movement speed scales allometrically and based on feeding type ${ }^{59}$, we drew $\beta_{x}$ and $\beta_{z}$ 589 from according normal distributions (carnivore: $\mu_{\beta}=0.42, \sigma_{\beta}=0.05$, omnivore: $\mu_{\beta}=0.19, \sigma_{\beta}=$ 5900.04 , herbivore: $\mu_{\beta}=0.19, \sigma_{\beta}=0.04$, primary producer: $\left.\mu_{\beta}=0, \sigma_{\beta}=0\right)$. Activation energy $E_{p}$ is 591 equal to -0.38 (Binzer et al. 2015). $L_{i j}$ is assumed to follow a Ricker curve (Schneider et al.

592 2016), defined as: $L_{x z}=\left(\frac{m_{x}}{m_{z} R_{o p t}} e^{1-\frac{m_{x}}{m_{z} R_{o p t}}}\right)^{\gamma}$

594 where the optimal consumer-resource body mass ratio $R_{o p t}=47.9$ was calculated from the 595 observed realised interactions in our dataset. We used a threshold $L_{i j}<0.01$ under which values 596 were set to 0 , assuming that too small or too large prey are not considered by consumers. The 597 handling time $h_{i j}$ of $i$ on $j$ is defined as:

$598 h_{i j}=h_{0} m_{i}^{\eta_{i}} m_{j}^{\eta_{j}} e^{E_{h} \frac{T_{0}-T}{k T_{0} T}}$,

599 where the scaling constant $h_{0}$ was set to 0.4 and the allometric coefficients for $\eta_{i}$ and $\eta_{j}$ where 600 drawn from a normal distribution with mean and standard deviation of -0.48 and 0.03 for $\eta_{i}$ and 601 of -0.66 and 0.02 for $\eta_{j}$. $E_{h}$ is equal to 0.26 . The term $w_{i j}$ informs on species selectivity ${ }^{60}$. For the 602 models without behavioural expectations we used the classical parametrisation and defined it 603 for every $j$ as 1 over the number of prey of consumer $i$. When adaptive behaviour was included 
604 in the model, the value was determined by the predictions of the skewed normal distribution we

605 fitted on our dataset. These were informed by the consumer and resource body masses, at

606 given levels of productivity and temperature. To maintain the comparability with the model

607 without adaptive behaviour, the $w_{i j}$ values were normalised to 1 for each consumer. As for our

608 experimental data, productivity was defined as the total biomass of prey available for each

609 consumer. As this value can be highly variable during the simulations, especially in the transient

610 dynamics, we rescaled this value between 0 and 4 to maintain it to a scale that is similar to the

611 one from our dataset that we used to inform the skew normal distributions

612 The biomass dynamic of the basal species $i$ is defined as:

$613 \frac{d B_{i}}{d t}=r_{i} G_{i} B_{i}-\sum_{j} B_{j} F_{j i}-x_{i} B_{i}$,

614 where $r_{i}=m_{i}^{-0.25}$ defines the species growth rate. $G_{i}$ is the species-specific growth factor,

615 determined by the concentration of two nutrients $N_{1}$ and $N_{2}$ :

$616 G_{i}=\min \left(\frac{N_{1}}{K_{i 1}+N_{1}}, \frac{N_{2}}{K_{i 2}+N_{1}}\right)$,

617 Where $K_{i l}$ determines the half saturation density of plant $i$ nutrient uptake rate. It is determined

618 randomly from a uniform distribution in $[0.1,0.2]$. The dynamic of the nutrient concentrations is

619 defined by:

$620 \frac{d N_{l}}{d_{t}}=D\left(S_{l}-N_{l}\right)-v_{l} \sum_{i} r_{i} G_{i} P_{i}$,

621 Where $D=0.25$ determines the nutrients turnover rate and $S_{I}=5$ determines the maximal

622 nutrient level. The loss of a specific nutrient I is limited by its relative content in the plant

623 '"species' biomass $\left(v_{1}=1, v_{2}=0.5\right)$.

624 We ran our model on food webs of 50 species, composed of 30 consumers and 20 basal

625 species. A link was drawn between two species $i$ and $j$ when $L_{i j}>0$. For each temperature we

626 ran 50 replicates of the two model's versions (with and without adaptive behaviour) and

627 recorded the number of extinctions. We fitted a GAM model on this number of extinctions 


\section{Supplementary information II: Environmental characteristics}

630

631 Overall, the different environments considered were characterised by two contrasted levels of 632 productivity, leading to a bimodal distribution.

633

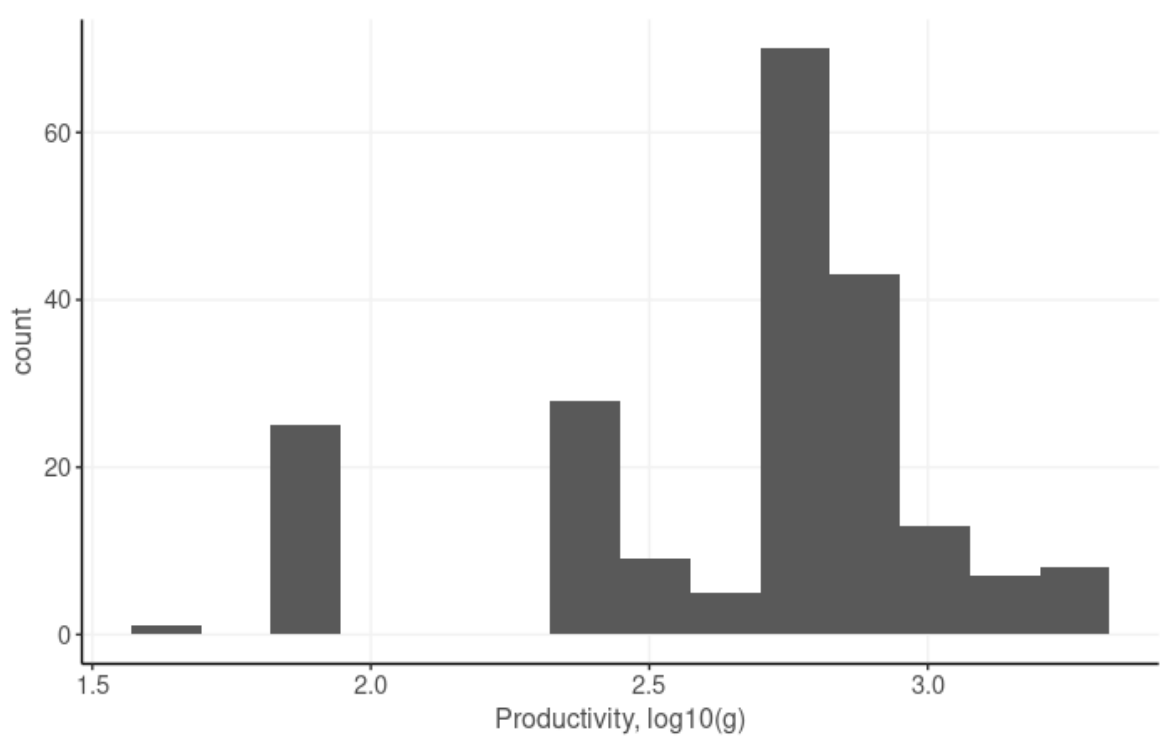

635 Fig. SI 2.1: distribution of the productivity values $(\mathrm{g})$ for the different environments

638 Associated to these differences, we observed that the body mass distribution of the basal

639 species (median and standard deviation) was responding differently to temperature depending 640 on productivity values (Figure SI 2.2, Table SI 2.1): 

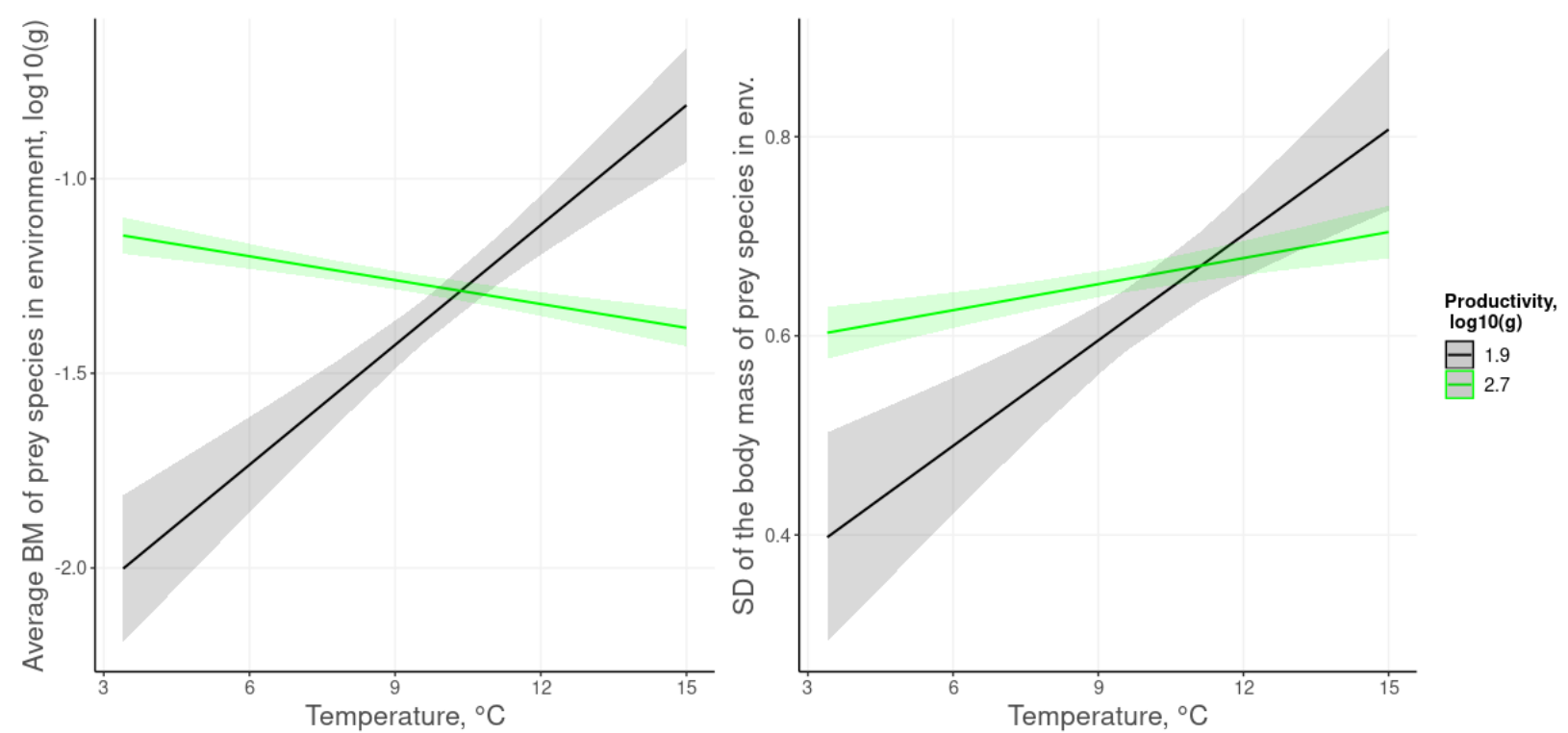

643

644

645

646

Fig. SI 2.2: response of the body mass structure of the resource species to temperature and productivity

Table SI 2.1: model estimate for the prediction of median and standard deviation of the environment distributions

\begin{tabular}{lcccccc}
\hline \hline & \multicolumn{3}{c}{ Median of BM } & \multicolumn{3}{c}{ Standard deviation of BM } \\
Predictors & Estimates & $C l$ & $p$ & Estimates & $C l$ & $p$ \\
\hline $\begin{array}{l}\text { Intercept) } \\
\text { Productivity }\end{array}$ & -5.38 & $-6.32--4.43$ & $<0.001$ & -0.43 & $-0.95-0.10$ & 0.113 \\
Temperature & 1.59 & $1.24-1.94$ & $<0.001$ & 0.37 & $0.17-0.57$ & $<0.001$ \\
productivity:temperature & -0.15 & $-0.19--0.12$ & $<0.001$ & -0.03 & $-0.05--0.01$ & 0.001 \\
\hline Observations & 223 & & & 223 & & \\
$R^{2} / R^{2}$ adjusted & $0.306 / 0.297$ & $0.30-0.49$ & $<0.001$ & 0.10 & $0.05-0.15$ & $<0.001$ \\
& & & & $0.160 / 0.148$ &
\end{tabular}

648

649 
653 As we observed a strong interaction effect between temperature and productivity when

654 explaining the response of the median of the body mass distributions in our different

655 environments, we estimated for which levels of productivity the relationship between

656 temperature and median was significant. At low productivity, we observed a positive slope

657 between the median and temperature albeit not significant. The slope of the regression linearly 658 decreased with productivity value, and became significantly lower than 0 for productivity levels 659 larger than $10^{2.52}$.

660

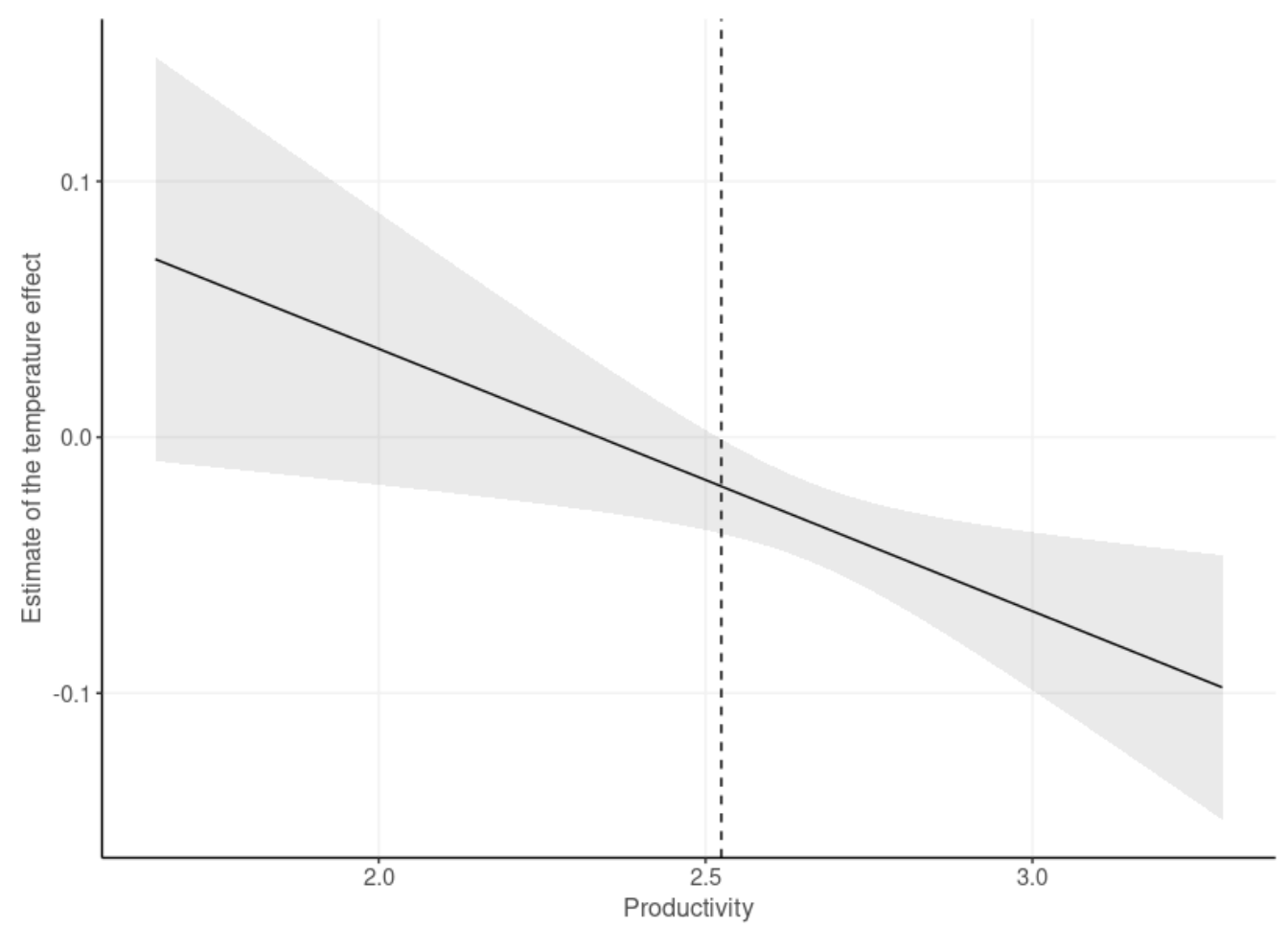

662 Fig. SI 3.1: Estimate and CI for the temperature effect at different levels of productivity. the dashed line indicates the productivity value above which the temperature effect become

664 significant 


\section{Supplementary information IV: response of the width of the preferred} trophic niche to local conditions

To assess how the width of the preferred niche responded to environmental conditions we fitted the same models as for the median on the standard deviation of the body mass of the preferred

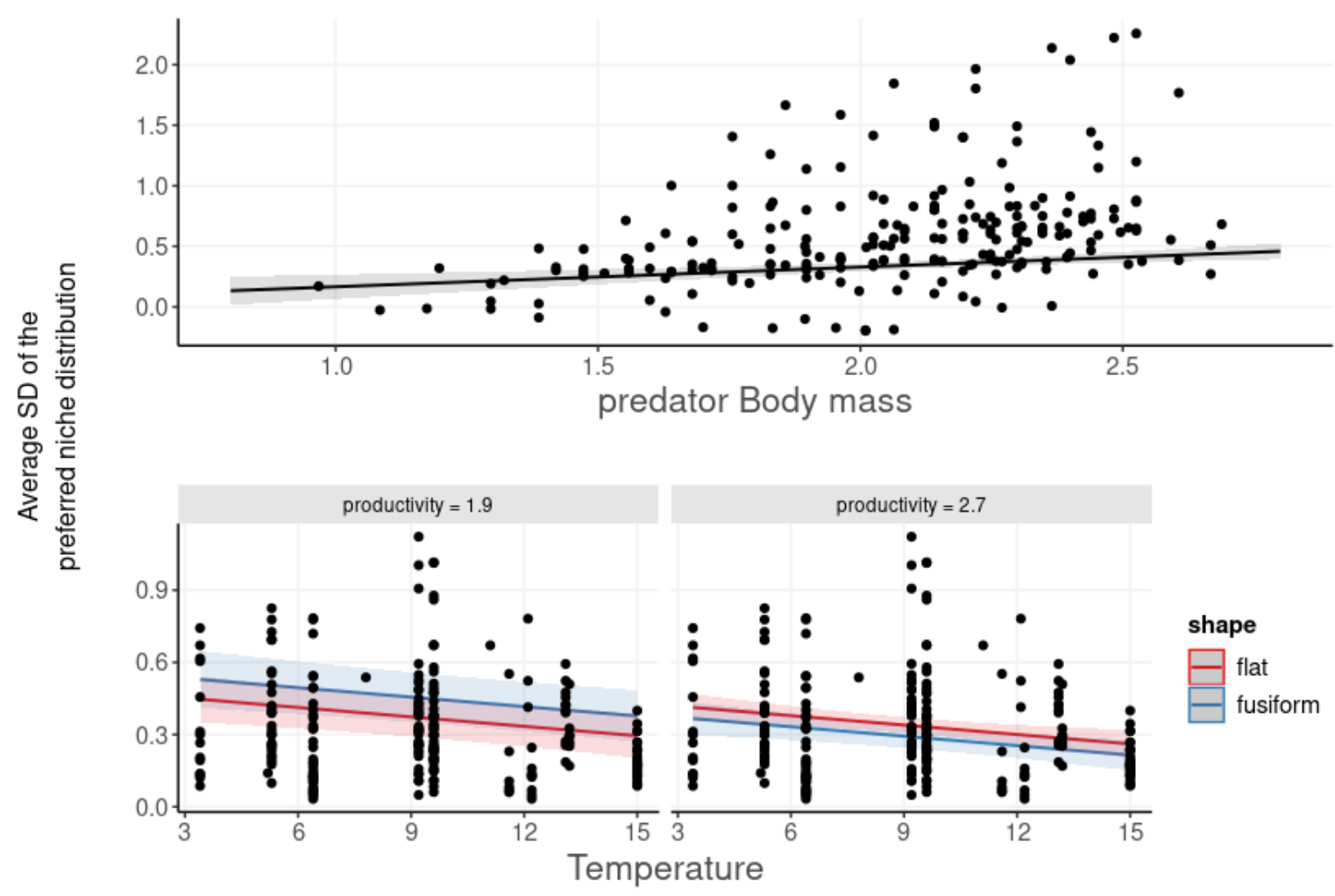

677 Fig. SI 4.1: Response of the width (standard deviation) of the preferred distribution to predator body mass (a) and temperature for different productivity gradients $(b, c)$. Colours define the fish shape. 
bioRxiv preprint doi: https://doi.org/10.1101/2021.05.05.442768; this version posted July 7, 2021. The copyright holder for this preprint (which was not certified by peer review) is the author/funder, who has granted bioRxiv a license to display the preprint in perpetuity. It is made available under aCC-BY-NC 4.0 International license.

681 Table SI 4.1: model estimates for the prediction of the standard deviation of the preference distributions

\begin{tabular}{lccc}
\hline \hline & \multicolumn{3}{c}{ sd of the preference distribution } \\
Predictors & Estimates & $C l$ & $p$ \\
\hline (Intercept) & 0.238 & $-0.075-0.551$ & 0.135 \\
Predator body mass & 0.163 & $0.078-0.247$ & $<0.001$ \\
Productivity & -0.043 & $-0.139-0.054$ & 0.384 \\
shapefusiform & 0.387 & $-0.027-0.802$ & 0.067 \\
Temperature & -0.013 & $-0.021--0.005$ & 0.001 \\
productivity:shapefusiform & -0.161 & $-0.314--0.007$ & 0.041 \\
\hline Observations & 223 & & \\
$\mathrm{R}^{2} / \mathrm{R}^{2}$ adjusted & $0.137 / 0.118$ & \\
& & &
\end{tabular}




\section{Supplementary information V: Effect of nutrient availability and}

686 predators' functional responses type on predictions about species

\section{7 coexistence.}

689 As maximum nutrient availability (variable $S_{i}$ ) and shape of the functional response $(q)$ are not

690 empirically informed, we analysed how sensitive to these two parameters model's predictions

691 are. We varied $S_{i}$ from 1 to 240 and q from 0 to 0.5 . Overall, we observed a very limited effect of

692 nutrient availability on the pattern observed (Fig. SI5.1). The type of the functional response

693 used resulted in more variations on the number of extinctions observed, but did not altered the

694 differences observed due to the incorporation of foraging behaviour (Fig. SI5.2). 
bioRxiv preprint doi: https://doi.org/10.1101/2021.05.05.442768; this version posted July 7 , 2021. The copyright holder for this preprint (which was not certified by peer review) is the author/funder, who has granted bioRxiv a license to display the preprint in perpetuity. It is made available under aCC-BY-NC 4.0 International license.

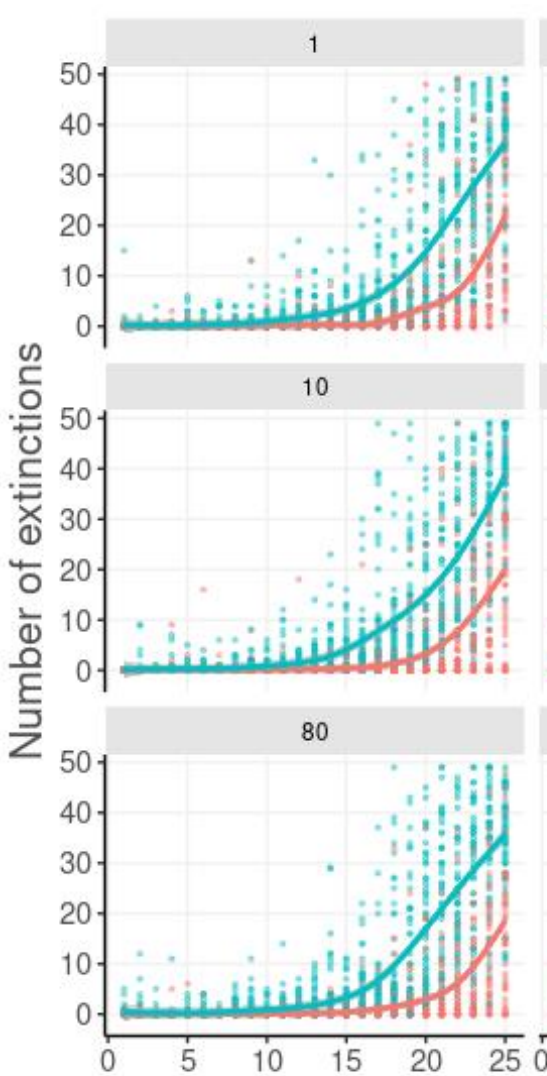

698

699

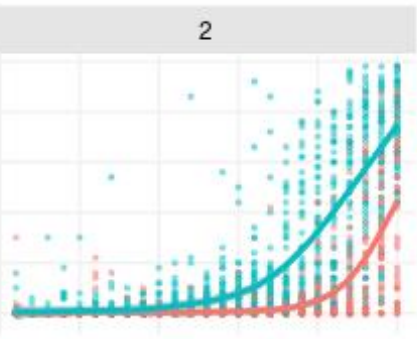

20
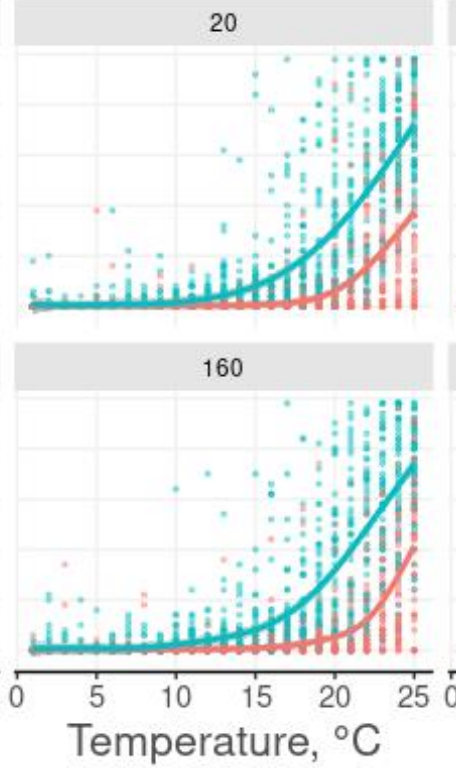

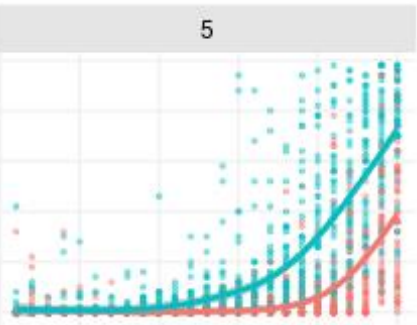

40

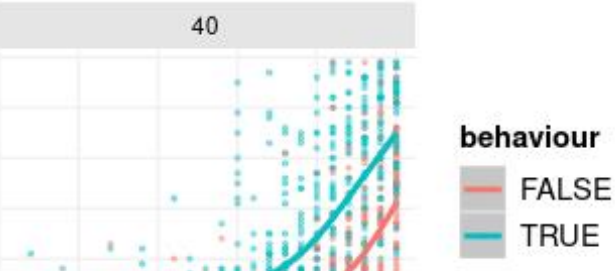

Figure SI 5.1: Effect of different levels of nutrient availability on the number of extinctions predicted by the model. Simulations where ran with a hill exponent (q) of 0.2 
bioRxiv preprint doi: https://doi.org/10.1101/2021.05.05.442768; this version posted July 7, 2021. The copyright holder for this preprint (which was not certified by peer review) is the author/funder, who has granted bioRxiv a license to display the preprint in perpetuity. It is made available under aCC-BY-NC 4.0 International license.

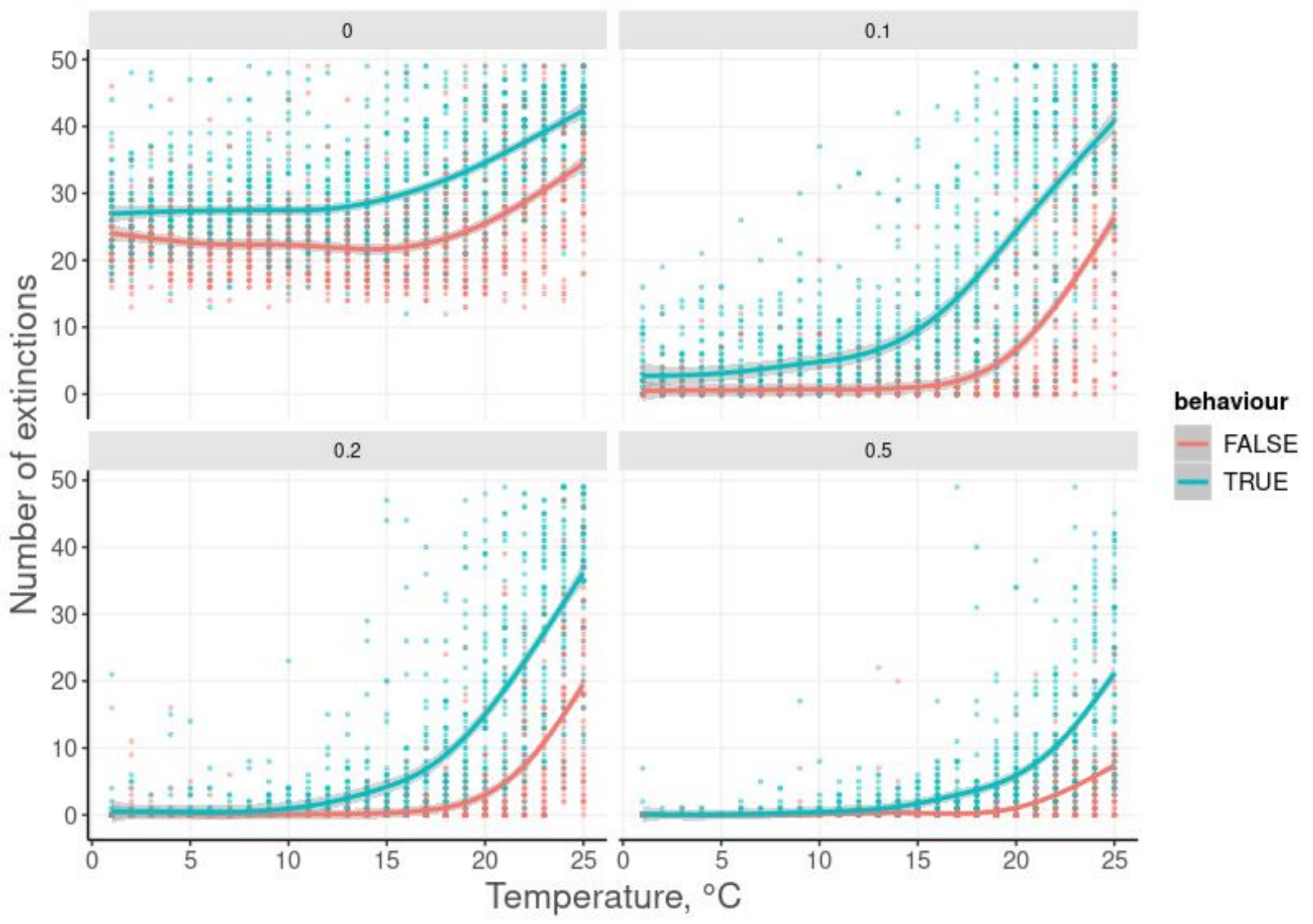

Figure SI5.2: effect of the choice of functional response type on the number of extinctions predicted by the model. Simulations where ran for a level of maximum nutrient (S) of 5 . 


\section{Supplementary information VI: Effect of considering different}

707 detection probabilities for prey in stomachs

As prey composed of soft tissues only are supposed to be less likely to be detected because of a faster digestion time, we corrected our observation by multiplying the abundance of species with hard body parts by 0.8 . This was done to mirror the importance of these species that should persist longer in stomachs. As we are missing a general framework to properly describe how digestion time changes for the different species we used a unique correction factor that is a free parameter in our model (prey are either easy or difficult to digest, Table SI 6.3). We here present the results we would have obtained without using this correction factor.

Results for the realised distributions

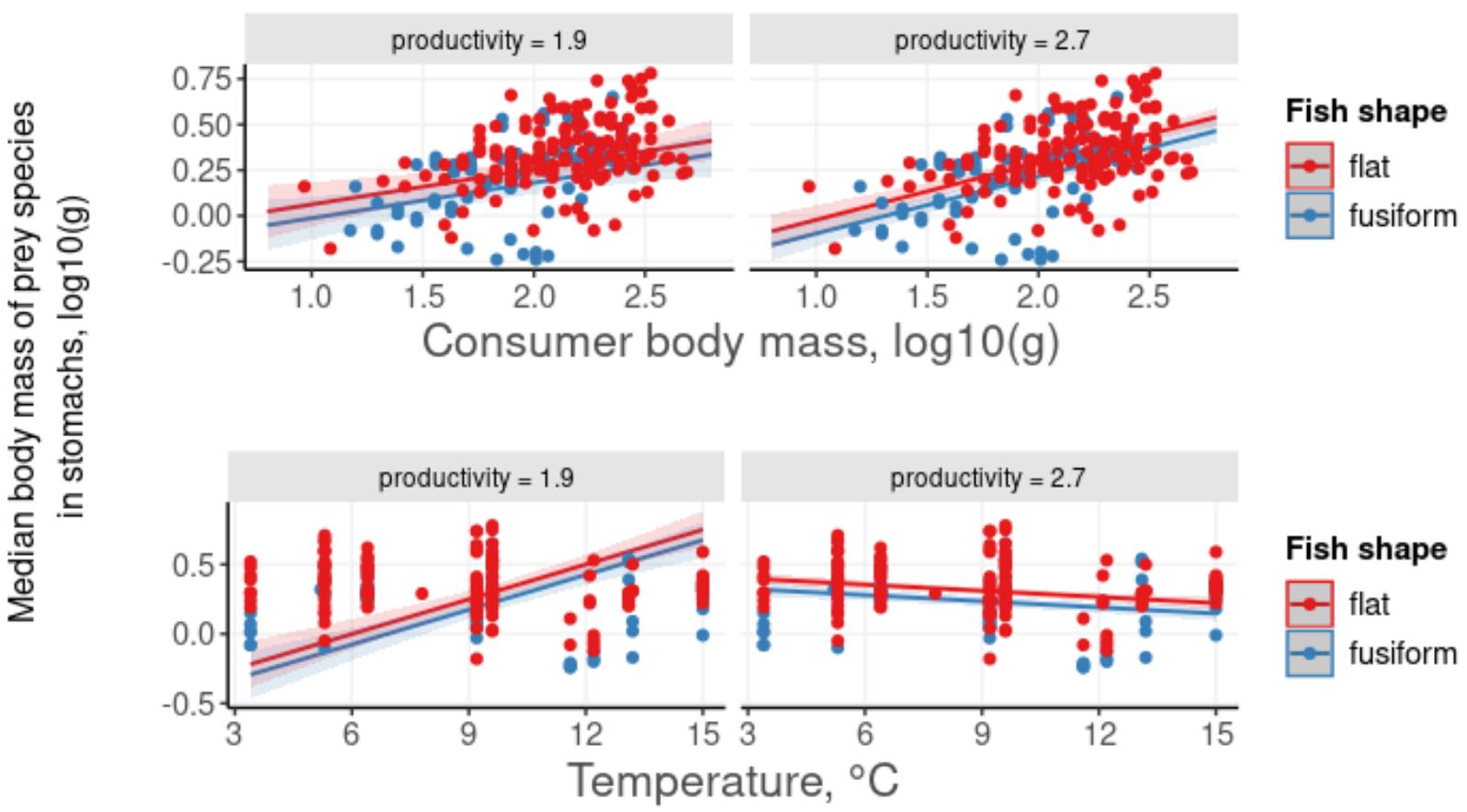

Figure S16.1: Response of the median body mass of the realised prey body mass distribution to predator body mass $(a, b)$, temperature $(c, d)$ at different productivity levels for the two fish shape. Points represent non-transformed data and lines present model predictions. The shaded areas show the 95\% confidence interval on the predicted values. Colours represent the fish functional groups (flat versus fusiforms). 
Table SI6.1: response of the realised distribution to predator body mass and environmental gradients

\begin{tabular}{lccc}
\hline \hline & \multicolumn{3}{c}{ Median of the realised distribution } \\
Predictors & Estimates & $C I$ & $p$ \\
\hline (Intercept) & -2.57 & $-3.64--1.50$ & $<\mathbf{0 . 0 0 1}$ \\
Predator body mass & -0.09 & $-0.47-0.29$ & 0.649 \\
Productivity & 0.88 & $0.47-1.28$ & $<\mathbf{0 . 0 0 1}$ \\
Shape (fusiform) & -0.08 & $-0.12--0.03$ & $\mathbf{0 . 0 0 1}$ \\
Temperature & 0.32 & $0.24-0.40$ & $<\mathbf{0 . 0 0 1}$ \\
pred. BM:Productivity & 0.15 & $0.00-0.30$ & $\mathbf{0 . 0 4 8}$ \\
Productivity:Temperature & -0.12 & $-0.15--0.09$ & $<\mathbf{0 . 0 0 1}$ \\
\hline Observations & 224 & & \\
$\mathrm{R}^{2} / \mathrm{R}^{2}$ adjusted & $0.450 / 0.435$ &
\end{tabular}
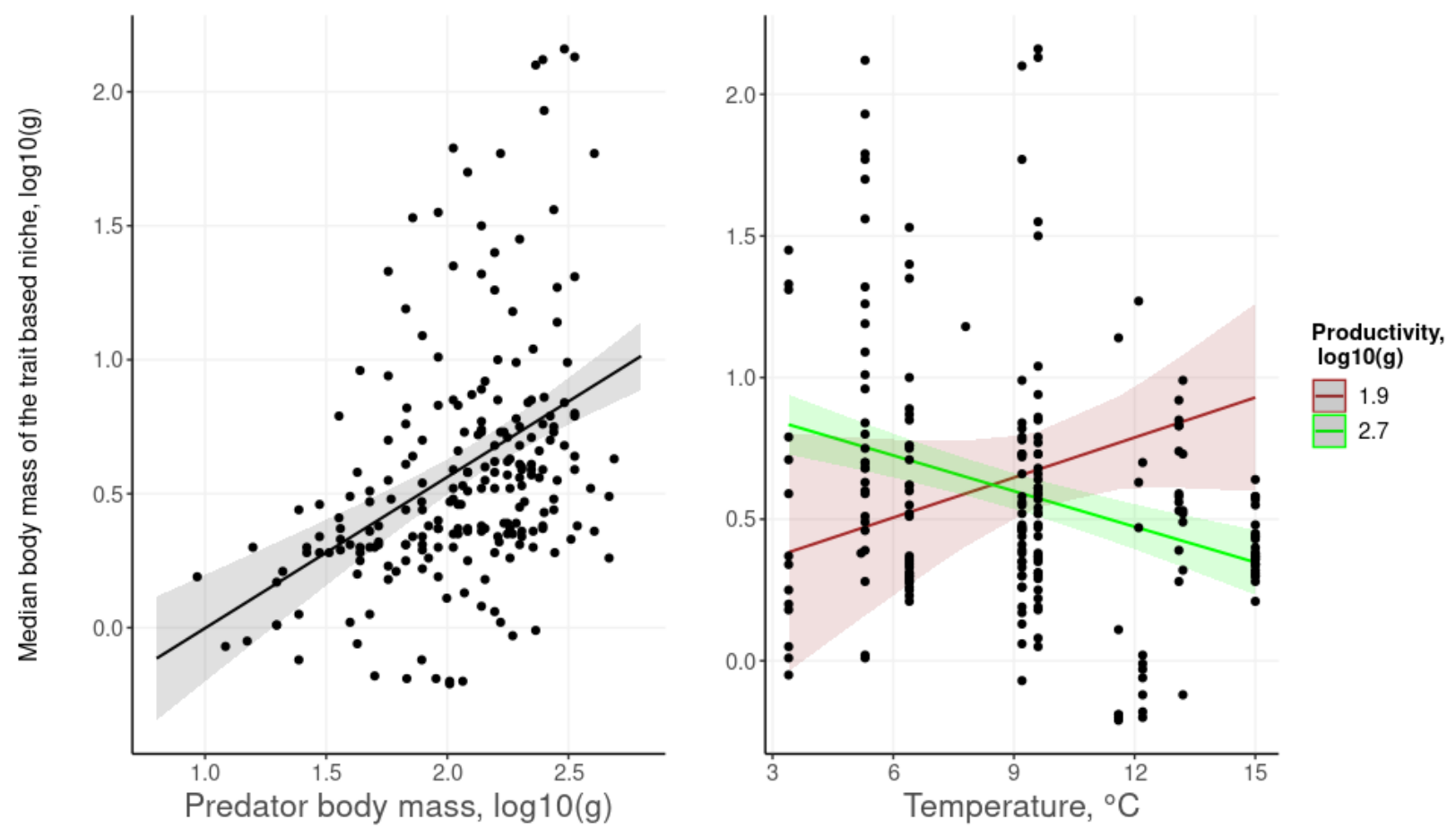

Figure S16.2: Response of the median body mass of the preference distribution to temperature, productivity, and fish body mass. Points represent non-transformed data and lines represent model predictions. The shaded areas show the 95\% confidence interval on the predicted values.
We can observe that the absence of correction factor does not qualitatively change the trends observed for the realised distributions. The variables selected by the AIC criteria are the same when correction for detectability was used. We can only detect slight changes in the model estimates. Grey and green colour represent two different productivity levels at which the temperature effect is represented 
Table SI 6.2: response of the preference distribution to predator body mass and environmental gradients

\begin{tabular}{lccc}
\hline \hline & \multicolumn{3}{c}{ Median of the preference distribution } \\
Estimates & $C I$ & $p$ \\
\hline (Intercept) & -1.252 & $-3.954-1.450$ & 0.362 \\
Predator body mass & -0.153 & $-1.115-0.809$ & 0.754 \\
Productivity & 0.392 & $-0.631-1.414$ & 0.451 \\
shapefusiform & -0.124 & $-0.238--0.011$ & $\mathbf{0 . 0 3 2}$ \\
Temperature & 0.259 & $0.051-0.466$ & $\mathbf{0 . 0 1 5}$ \\
pred.BM:productivity & 0.268 & $-0.103-0.639$ & 0.156 \\
Productivity:Temperature & -0.111 & $-0.189--0.033$ & $\mathbf{0 . 0 0 5}$ \\
\hline Observations & 224 & & \\
$\mathrm{R}^{2} / \mathrm{R}^{2}$ adjusted & $0.282 / 0.262$ & &
\end{tabular}

\section{SIVI.2).}

Classification of species' digestibility

\begin{tabular}{llr} 
Prey species & Class & Digestibility \\
\hline Abra alba & Bivalvia & Hard \\
\hline Aloidis gibba & Bivalvia & Hard \\
\hline Amphicteis gunneri & Polychaeta & Easy \\
\hline Amphipoda spp. & Malacostraca & Easy \\
\hline Anaitides spp. & Polychaeta & Easy \\
\hline Anthozoa spp. & Anthozoa & Easy \\
\hline Aphia minuta & Actinopterygii & Hard \\
\hline Aphroditidae spp. & Polychaeta & Easy \\
\hline Arenicola marina & Polychaeta & Easy \\
\hline Ascidiacea spp. & Ascidiacea & Easy \\
\hline Astarte spp. & Bivalvia & Hard \\
\hline Balanus spp. & Hexanauplia & Hard \\
\hline Brada villosa & Polychaeta & Easy \\
\hline Capitella capitata & Polychaeta & Easy \\
\hline Carcinus maenas & Malacostraca & Hard \\
\hline Cardium fasciatum & Bivalvia & Hard \\
\hline Castalia punctata & Polychaeta & Easy \\
\hline Clupea harengus & Actinopterygii & Hard \\
\hline & &
\end{tabular}




\begin{tabular}{|c|c|c|}
\hline Corophium spp. & Malacostraca & Easy \\
\hline Crangon crangon & Malacostraca & Hard \\
\hline Cumacea spp. & Malacostraca & Easy \\
\hline Mysidacea spp. & Malacostraca & Hard \\
\hline Cyprina islandica & Bivalvia & Hard \\
\hline Diastylis rathkei & Malacostraca & Easy \\
\hline Disoma multisectosum & Polychaeta & Easy \\
\hline Euchone papillosa & Polychaeta & Easy \\
\hline Gastosaccus spinifer & Malacostraca & Hard \\
\hline Gobiidae spp. & Actinopterygii & Hard \\
\hline Halicryptus spinolosus & Halicryptomorpha & Hard \\
\hline Harmothoe imbricata & Polychaeta & Easy \\
\hline Harmothoe spp. & Polychaeta & Easy \\
\hline Hyperia galba & Malacostraca & Easy \\
\hline Idothea spp. & Malacostraca & Hard \\
\hline Isopoda spp. & Malacostraca & Hard \\
\hline Limanda limanda & Actinopterygii & Hard \\
\hline Macoma spp. & Bivalvia & Hard \\
\hline Metridium senile & Anthozoa & Hard \\
\hline Microdeutopus sp. & Malacostraca & Easy \\
\hline Musculus spp. & Bivalvia & Hard \\
\hline $\begin{array}{l}\text { Mya truncata, Mya } \\
\text { arenaria }\end{array}$ & Bivalvia & Hard \\
\hline Mysis mixta & Malacostraca & Hard \\
\hline Mytilus edulis & Bivalvia & Hard \\
\hline Nemertea spp. & Nemertea & Easy \\
\hline Nephthys spp. & Polychaeta & Easy \\
\hline Nucula nitida & Bivalvia & Hard \\
\hline Ophiura albida & Ophiuroidea & Hard \\
\hline Other Decapoda & Decapoda & Hard \\
\hline Other Gastropoda & Gastropoda & Hard \\
\hline Other Polychaeta & Polychaeta & Easy \\
\hline Pectinaria koreni & Polychaeta & Easy \\
\hline Phaxas pellucidus & Bivalvia & Hard \\
\hline Pherusa plumosa & Polychaeta & Easy \\
\hline $\begin{array}{l}\text { Phtisica marina, } \\
\text { Caprella }\end{array}$ & Malacostraca & Easy \\
\hline Pisces spp. & Actinopterygii & Hard \\
\hline Pleuronectiformes spp. & Actinopterygii & Hard \\
\hline Polydora sp. & Polychaeta & Easy \\
\hline $\begin{array}{l}\text { Pomatoschistus } \\
\text { minutus }\end{array}$ & Actinopterygii & Hard \\
\hline
\end{tabular}


bioRxiv preprint doi: https://doi.org/10.1101/2021.05.05.442768; this version posted July 7, 2021. The copyright holder for this preprint (which was not certified by peer review) is the author/funder, who has granted bioRxiv a license to display the preprint in perpetuity. It is made available under aCC-BY-NC 4.0 International license.

761

\begin{tabular}{llr} 
Priapulus caudatus & Priapulida & Easy \\
\hline Saxicava arctica & Bivalvia & Hard \\
\hline Scoloplos armiger & Polychaeta & Easy \\
\hline Spionidae spp. & Polychaeta & Easy \\
\hline Terebellides stroemi & Polychaeta & Easy \\
\hline Thyonidium pellucidum & Holothuroidea & Hard \\
\hline
\end{tabular}

